\title{
RESIDENTIAL BUILDINGS AND THE COST OF CONSTRUCTION: NEW EVIDENCE ON THE EFFICIENCY OF THE HOUSING MARKET
}

\author{
Stuart S. Rosenthal*
}

\begin{abstract}
Present value studies of asset market efficiency are controversial because they compare asset prices to unobserved discounted streams of future rents. As an alternative, if housing markets are efficient, then the price of residential capital or buildings should satisfy the following two conditions: (i) deviations between new building prices and construction costs should disappear faster than construction lags and have no effect on construction, and (ii) temporary building price shocks should dissipate at a similar rate for different vintage buildings. Results from an errorcorrection model support both hypotheses for single-family housing in Vancouver, British Columbia. This implies that the implicit market for residential buildings is efficient and that any inefficiencies in the housing market must lie in the market for land itself.
\end{abstract}

\section{Introduction}

$\mathrm{T}_{\mathrm{s}}$ HE DEGREE to which asset markets are efficient is a question that has far-reaching implications for resource allocation in the economy. For that reason, attention to this question has been broad in scope, encompassing exchangerate markets, stock and bond markets, and durable assets like real estate. Most often, researchers have sought to test whether asset prices equal discounted streams of expected future dividends (rents), the asset's "fundamental value," a condition that should hold in equilibrium when all excess profit opportunities have been arbitraged away. Evidence that an asset price differs from its fundamental value in a persistent manner signals the presence of arbitrage opportunities and an inefficient market.

Yet, despite enormous amounts of work in this area, the question of whether asset markets are efficient remains controversial. That controversy stems, in part, from the fact that discounted streams of expected future dividends are unobservable. As noted by Stiglitz (1990), a common response to the absence of direct information about fundamental values has been to seek indirect empirical evidence for violations of the present value relationship. ${ }^{1}$ Partly for

Received for publication July 17, 1996. Revision accepted for publication June 5, 1998.

* Virginia Polytechnic Institute and State University.

Special thanks go to Stan Hamilton for providing me access to the data on home sales. I would like to thank Jim Nason, Denise DiPasquale, Will Strange, Bob Helsley, Larry Jones, Tsur Somerville, Dennis Epple, and Susan Wachter for helpful conversations. Comments from seminar participants at Harvard University, Tufts University, the University of Connecticut, and the University of Florida are also appreciated. Any errors of course, are the responsibility of the author. Financial support from the Social Science and Humanities Research Council (SSHRC) of Canada and the Real Estate Institute of British Columbia (REIBC) is gratefully acknowledged.

${ }^{1}$ Shiller (1981), for example, compared stock-price volatility to the volatility of expected future streams of dividends. Findings indicated that stock-price volatility exceeded levels that would be supported by expected dividend streams. More recently, Froot and Obstfeld (1991) argued that previous studies had mistakenly assumed that asset prices respond to changes in fundamental values in linear manner. Froot and Obstfeld demonstrate that their nonlinear "intrinsic" rational-bubbles model does a good job of replicating stock-price movements over the last century. Donaldson and Kamstra (1996) argue that prior studies erred by using ex that reason, however, Flood and Hodrick (1990) argue that studies proporting to show that asset prices do not satisfy the present value relationship likely suffer from model misspecification, and, as such, do not provide evidence that asset markets are inefficient.

This paper takes a different approach to the question of asset market efficiency by focusing on two alternative equilibrium conditions that govern the implicit market for residential buildings, where building is defined here and throughout this paper as the physical structure apart from the land on which it rests. Drawing on models of urban redevelopment, it is shown that, in long-run equilibrium, the price of a newly constructed building equals current construction costs, while the price of an older building also depends on past and current values of the relative cost of vacant land to capital. In addition, with efficient markets in equilibrium, the expected risk-adjusted rates of return across assets will be equal.

Building from these equilibrium conditions, the principal hypothesis to be tested is that, if the market for residential buildings is efficient, then any deviations between new building prices and construction costs should disappear more quickly than the time required for construction, thereby eliminating excess profit opportunities for builders. Under those conditions, temporary shocks to new building prices should not affect construction activity. If, instead, new building prices converge back to construction costs more slowly than construction lags, builders would likely have an incentive to adjust production in response to contemporaneous deviations between building prices and construction costs. Under those conditions, one would expect periodic surges and dearths in construction activity that would be unwarranted given real underlying economic fundamentals.

The above argument suggests that construction lags likely influence the rate at which new building prices converge back to equilibrium following a temporary shock. That argument does not necessarily imply a relationship between construction lags and older building prices since builders market new, as opposed to existing, buildings. Suppose, however, that investors view new and existing buildings as close substitutes (as seems reasonable for single-family detached properties). Then, with efficient markets, investments in different vintage buildings should entail similar risk and yield similar expected returns. Under those conditions, one would expect the prices of different vintage buildings to respond to shocks in a similar fashion. Older vintage building prices should, therefore, converge back to equilib-

post streams of dividends to calculate fundamental values. When Donaldson and Kamstra estimate fundamental values using only information available to investors on an ex ante basis, they conclude that the stock market boom and bust of the 1920s was not a bubble. 
rium at a rate similar to that of new building prices. Accordingly, while construction lags have a direct effect on the rate at which new building prices converge to equilibrium following a shock, they also have an indirect effect on older building prices because of the willingness of investors to substitute new for existing buildings.

Both of the empirical tests above depend only on current and past variables. That feature greatly facilitates estimation relative to present-value studies by precluding the need to forecast future rents. Moreover, given the focus on rates of price convergence to long-run values, an error correction model (ECM) provides an intuitive and convenient way to evaluate the two hypotheses. In order to estimate the ECM, however, it was necessary to first construct the relevant price series. That task was accomplished using a unique data set comprising more than 25,000 single-family detached home sales in ten spatially concentrated neighborhoods in Vancouver, B.C., from 1979 through 1989. Given these data, hedonic methods were used to decompose quality-adjusted house prices into the price of vacant land and the qualityadjusted price of a building, where a separate index was constructed for new buildings, 25-year-old buildings, and 35 -year-old buildings. Construction costs were measured by a local construction cost index.

The ECM was estimated using the Engle-Granger (1987) two-step method, in which the equations were stacked at each stage for the three building prices and estimated by SUR to enhance efficiency. ${ }^{2}$ Findings indicate that new building prices significantly deviated from construction costs several times over the 44-quarter horizon, with a dramatic episode of overpricing in 1981 . However, $80 \%$ of the shock to new building prices disappears within one quarter, while $95 \%$ of a price shock is eliminated after two quarters. For older buildings, the rates of convergence are $70 \%$ and $90 \%$ after one and two quarters, respectively. Moreover, the rates of convergence did not differ significantly across vintages, consistent with the joint hypothesis that investors view different-vintage buildings as close substitutes, and that different-vintage properties yield equal expected-risk adjusted rates of return.

Further analysis indicates that two to three quarters are required to complete a new single-family building in Vancouver. Thus, the transactions costs associated with putting up a new building - as measured by the time to complete a project-appear to offset potential arbitrage opportunities arising from short-run building price shocks. That hypothesis is supported by additional analysis that shows that deviations between new building prices and construction cost have no discernible effect on residential construction. Overall, these findings provide strong evidence that the market for residential buildings is efficient.

Finally, it should be stressed that the degree to which real

\footnotetext{
${ }^{2}$ A third stage based on Engle and Yoo (1991) was added to ensure that the standard errors from the cointegrating equations have standard limiting distributions.
}

estate markets are efficient is of central importance for the economy. Among homeowners, the great majority of household wealth is held in home equity. Partly for that reason, Case and Shiller (1991) argue that an unwarranted boom in real estate prices in Boston in the latter half of the 1980s contributed to a boom and subsequent bust in consumer spending and residential construction that proved catastrophic for the Boston economy. Consider, however, that, in most cities across North America, buildings account for roughly $70 \%$ of single-family detached property values, while land accounts for $30 \%{ }^{3}$ Thus, the evidence presented here suggests that the principle component to housing, namely the building itself, is priced in an efficient manner. If housing markets are inefficient-as claimed by Case and Shiller (1989) and others-the inefficiency must therefore reside in the market for land itself.

To clarify these issues, section II reviews previous studies on the efficiency of the housing market. Section III describes the economic determinants of land and building prices. Section IV presents the data and hedonic methodology used to construct the price series. Section V presents descriptive measures of the data and describes the error correction model. Section VI presents the principal results, and section VII concludes.

\section{A Brief Review of Prior Studies on the Efficiency of the Housing Market}

While the literature on housing market efficiency has been varied both in emphasis and in methodologies, many prior studies can be broadly grouped into three areas: papers that test whether quality-adjusted house prices equal the discounted present value of their rents (fundamental value); papers that examine whether house prices display serial correlation and are, therefore, forecastable; and papers that express changes in house prices as functions of changes in their real determinants (e.g., income, employment, net migration, inventories, and the like). Regardless of approach, most papers find evidence that, on the surface, could suggest that real estate markets may be inefficient.

Clayton (1994) and Meese and Wallace (1994), for example, both find that house values deviate from fundamental values in the short run, although the present-value relationship appears to hold in the long run. Hosios and Pesando (1991) and Case and Shiller (1989) find evidence that quality-adjusted house prices are serially correlated on a quarterly basis, which implies that future house prices are forecastable. Similarly, Linneman (1986) finds that portfolios of "negative residual" homes appreciate markedly

\footnotetext{
${ }^{3}$ Somerville (1994) quotes Commerce Department sources as estimating that structures account for roughly $70 \%$ of residential house values in urban areas in the United States. In contrast, data presented later in the paper indicate that structures account for roughly $50 \%$ of single-family detached house values in Vancouver, B.C. The lower value for Vancouver reflects the especially high price of land in Vancouver relative to other urban markets in North America.
} 
faster than a random sample of homes in the residential market, in which the residuals are the error terms from a hedonic regression estimated at a given point in time. ${ }^{4}$ Most prominently, in a much-cited paper, Mankiw and Weil (1989) argue that forecastable demographic changes arising from the aging of the baby-boom generation are good predictors of real changes in U.S. house prices. ${ }^{5}$

At first glance, findings from these papers violate the efficient-markets hypothesis and imply the presence of arbitrage opportunities on a risk-adjusted basis. On the other hand, in characterizing their results, Meese and Wallace (1994) write

Whether these findings constitute evidence of selffulfilling expectations, market inefficiency, or irrational behavior on the part of participants in the San Francisco area housing market will depend on the priors of our readers. We find the argument for bubbles or irrational behavior in the Bay Area housing market less compelling than an explanation based on the high transactions costs that are known to characterize the market.

Two striking messages can be gleaned from this statement. First, it is important to take transactions costs into account when assessing the efficiency of the real estate market, and second, measures of transactions costs are difficult to obtain. In that sense, Meese and Wallace recognize that their findings could reflect misspecification of the model and do not provide concrete evidence either in favor of or against the notion that real estate prices might periodically diverge from fundamental values. More generally, all of the studies cited above potentially suffer from Flood and Hodrick's (1990) critique noted earlier. ${ }^{6}$

In the present paper, transactions costs are measured by the time to complete a new building. That lag is then compared to the speed with which the price of a new building converges back to construction costs following a shock. In addition, under the assumption that investors view different-vintage buildings as close substitutes, the rate at which older-vintage building prices converge back to equilibrium following a shock should be similar to that of new buildings and, therefore, less than construction lags. For

\footnotetext{
${ }^{4}$ Linneman (1986) argues that the residuals from a hedonic house price regression include transactor errors that have mean zero over time. As such, a portfolio of properties with negative residuals is expected to display above-average appreciation. Linneman's results support that hypothesis.

${ }^{5}$ In contrast, when Engelhardt and Poterba (1992) replicate the MankiwWeil analysis using Canadian data, they fail to find evidence that forecastable demographic trends are good predictors of real future house-price movements. In addition, DiPasquale and Wheaton (1994) point out that Mankiw and Weil (1989) ignored the supply side of the housing market. When DiPasquale and Wheaton take the supply side of the housing market into account using U.S. data, most of the impact of demographic change on house prices disappears.

${ }^{6}$ Of the studies cited above, only Linneman (1986) models transactions costs by comparing the expected return on negative-residual portfolios (as defined in note 4) of single-family homes to the transactions costs of buying and selling a home. Linneman concludes that, with transactions costs equal to $12 \%$ of house value, speculators would generally not profit from the high appreciation rate on negative-residual portfolios.
}

both hypotheses, it should be stressed that it is not necessary to measure the dollar value of the transactions cost of trading real estate. Instead, because the testable hypotheses are based on the rate at which building prices converge to their long-run values, transactions costs can be characterized by the speed with which builders can respond to profit-making opportunities.

\section{Vacant Land and Building Prices in a Model with Redevelopment}

\section{A. The Equilibrium Condition}

In order to decompose house prices into their vacant land and building price components, it is important to first clarify those factors that affect the prices of vacant land and buildings. As will become apparent, the existing literature on urban redevelopment offers considerable insight into this problem. ${ }^{7}$ Assume that lots are of equal size, and that the lot size is fixed and normalized to $1 .{ }^{8}$ Housing capital $(s)$ is durable but depreciates at a positive unknown rate that can change over time, housing is subject to periodic redevelopment, and renovations are not allowed. Property owners are assumed to maximize property value by choosing an optimal sequence of redevelopment dates and associated levels of capital (building types), subject to construction costs and the initial stock of housing capital. The unit cost of construction (c) at time $t$ is the same in all locations, and the cost of demolishing a structure is zero. ${ }^{9}$ Optimal future building types are uncertain, and all land has been previously developed.

Given this framework, several principles arise from the theoretical literature on urban redevelopment that are pertinent to the discussion below. First, urban landowners hold a call option that gives them the right but not the obligation to develop (redevelop) their property. Before constructing a building, builders must purchase such an option by acquiring a parcel of land. With efficient markets, the value of the development option is equal to the value of uncertain future development opportunities as determined by underlying market fundamentals. The price of vacant land, therefore, is

\footnotetext{
${ }^{7}$ The literature on the optimal timing of urban land development can be grouped into two categories for the purposes of this paper: studies that examine urban growth and redevelopment with myopic expectations, such as Brueckner (1980) and Wheaton (1982), and studies that examine the optimal timing of urban development in the presence of uncertainty over future preferred uses of the land, such as Titman (1985), Capozza and Helsley (1989), Williams (1997), and Childs et al. (1997).

${ }^{8}$ These assumptions do not affect the qualitative nature of the discussion below but simplify exposition. For the empirical work, lot size is allowed to vary across properties while the assumption of fixed lot sizes over time is retained because most lots in the sample are small and there is little opportunity to join adjacent lots.

${ }^{9}$ Given that the home sales in this paper are taken from ten small adjacent areas, unit construction costs are almost certainly alike for all properties in a given period. Also, demolition costs for single-family detached homes in Vancouver, B.C., are a small fraction of lot values, which is why demolition costs are set to zero (e.g., Rosenthal \& Helsley, 1994). More generally, one can incorporate demolition costs by redefining $c_{t}$ to include the cost of demolishing the existing structure.
} 
equal to the value of the development option (e.g., Titman, 1985). The price of previously developed land is equal to the value of the development option (vacant land) plus the discounted stream of rents from the current building up to the next redevelopment date (e.g., Rosenthal \& Helsley, 1994).

With efficient markets, landowners exercise their development option when the net profit from developing today is slightly greater than the cost of the option. Approximating, a parcel of urban land is redeveloped when the price of land upon redevelopment, $P_{t j}^{D}(s(t))$, less construction costs, $c_{t} s_{t}(t)$, is equal to the price of acquiring the parcel of land in its present state, $P_{t j}^{D}(s(t-a))$,

$$
P_{t_{j}}^{D}(s(t))-c_{t} s_{t}(t)=P_{t_{j}}^{D}(s(t-a))
$$

where $s_{t}(t-a)$ is the level of housing capital at time $t$ in an age $a$ building, $a=0$ implies a new building, and $c_{t}$ is the unit cost of housing capital. The redevelopment rule in equation (3.1) was first described in models with myopic expectations by Brueckner (1980) and Wheaton (1982 in refs). Titman (1985) arrived at essentially the same development rule in a model with vacant land and uncertainty over optimal future uses of the land, provided $P_{t j}^{D}(s(t-a))$ is interpreted to include an uncertainty premium. ${ }^{10}$ Empirical support for equation (3.1) has recently been provided by Rosenthal and Helsley (1994) using single-family detached homes in Vancouver, B.C., the same market studied in this paper. ${ }^{11}$

An important implication of equation (3.1) is that, with efficient markets, when a previously developed property is sold for redevelopment, the existing building has zero value because it is demolished upon sale. Upon redevelopment, therefore, $s_{t}(t-a)$ equals zero, and properties purchased for redevelopment are, in actuality, vacant land sales (e.g., Rosenthal \& Helsley, 1994). It follows that the price of vacant land at time $t$ and location $j, P_{t j}^{L}$, is given by the left-hand side of equation (3.1),

$$
P_{t_{j}}^{L}=P_{t_{j}}^{D}(s(t))-c_{t} s_{t}(t)
$$

The price at time $t$ of a vintage $t-a$ building at location $j$ is now defined as the difference between $P_{t j}^{D}(s(t-a))$ and

\footnotetext{
10 Titman (1985) shows that, with risk-neutral investors, uncertainty over future unit (quality-adjusted) building prices increases the value of the development option and, therefore, the price of land. This arises because optimal building types vary in response to changes in the unit price of buildings, causing the land valuation function to be convex. (See Titman (1985) for details.) In the present context, the principal effect of uncertainty is that $P_{t j}^{D}(s(t-a))$ should be interpreted to include an uncertainty premium, the magnitude of which varies with the level of uncertainty. As will become apparent, that premium differences out of the problem when developing the estimating equations below.

${ }^{11}$ Munneke (1996) also obtains empirical support for the redevelopment rule in equation (3.1) for commercial and industrial property in Chicago.
}

$P_{t j}^{L}$. Substituting for $P_{t j}^{L}$ from equation (3.2) and simplifying, ${ }^{12}$

$$
\begin{aligned}
P_{t}^{B}(s(t-a)) & \equiv P_{t_{j}}^{D}(s(t-a))-\left[P_{t_{j}}^{D}(s(t))-c_{t} s_{t}(t)\right] \\
& =c_{t} s_{t}(t)-\left[P_{t}^{B}(s(t))-P_{t}^{B}(s(t-a))\right] .
\end{aligned}
$$

Equation (3.3) is the zero-profit condition for builders when markets are efficient. To understand why, note that a developed parcel of land can always be converted into vacant land by demolishing the existing structure, and recall that $P_{t j}^{L}$ equals the value of the development option. The development option, therefore, is embedded in a given property both before and after redevelopment. Recall, also, that if land is redeveloped when equation (3.1) is satisfied, properties purchased for redevelopment are valued as vacant land. With efficient markets, therefore, the builder's costs include the development option $P_{t j}^{L}$ plus construction costs $c_{t} s_{t}{ }^{13}$ The builder's revenues equal $P_{t j}^{L}$ plus the price of a new building $P_{t}^{B}(s(t))$ : builders sell a package to homebuyers that comprises the development option plus the new building. Hence, $P_{t j}^{L}$ differences out of net profits and, with net profits set to zero, $c_{t} s_{t}$ equals $P_{t}^{B}(s(t))$.

\section{B. Deviations Between $\mathrm{P}_{\mathrm{t}}^{\mathrm{B}}(\mathrm{s}(\mathrm{t}))$ and $\mathrm{c}_{\mathrm{t}} \mathrm{s}_{\mathrm{t}}$ and Excess Profits}

Suppose now, that in a given urban area, there is a continuous distribution of existing building types $s(t-a)$ such that, at any given time, a subset of the stock of urban land is ready for redevelopment in the sense that housing capital has depreciated to the point that equation (3.1) is satisfied. Suppose also that new building prices deviate from construction costs by an amount $\eta_{t}$, builders observe $\eta_{t}$ contemporaneously but homebuyers do not, and

$$
P_{t}^{B}(s(t))=c_{t} s_{t}(t)+\eta_{t} \text { with } \eta_{t}=\iota_{t}+\delta \eta_{t-1},
$$

where $E\left[\mathbf{t}_{t}\right]=0$ and $0<\delta<1$. In addition, there is a lag between the time a builder starts a project and when the newly developed property is ready for sale.

As $\delta$ approaches zero, builders cannot earn excess profits from contemporaneous information about $\eta_{t}$, because building price converges back to construction costs faster than construction lags: if a builder begins a project today, the builder expects that, by the time the project is ready for sale, $\eta_{t}$ will equal zero and building price on average will equal construction costs. However, as $\delta$ approaches 1, builders expect current deviations between building prices and construction costs to persist beyond construction lags. In that case, land that would have just satisfied the redevelop-

\footnotetext{
${ }^{12}$ Although $P_{t j}^{L}$ is sensitive to locational amenities, $P_{t}^{B}(s(t-a))$ depends on the level of capital and construction costs. For that reason, $P_{t}^{B}(s(t-a))$ is not indexed by $j$.

${ }^{13}$ If, instead, a property was prematurely redeveloped in the sense that the existing structure had not depreciated to the point where equation (3.1) was satisfied, then the cost of redeveloping that property would include the discounted stream of remaining rents from the existing building.
} 
ment rule in equation (3.1) with $\eta_{t}$ equal to zero will instead provide builders with a positive expected return. In addition, some land that would have been unprofitable to develop with $\eta_{t}$ equal to zero will be prematurely redeveloped. Thus, as $\delta$ gets large, contemporaneous knowledge of $\eta_{t}$ likely allows builders to earn excess returns and also affects the level of construction.

There are two caveats to this argument that should be noted for completeness. First, the cost of obtaining land for development must not itself be mispriced in a manner that could offset profits associated with $\eta_{t}$. That condition is likely to be satisfied because builders both purchase and sell their development option causing any mispricing of the development option to be at least partially differenced away. ${ }^{14}$ Moreover, for homes not built on spec, the homebuyer (or some other agent) first purchases a parcel of land and then hires a builder: in that case, the builder does not serve as a land "intermediary," and mispricing of the development option clearly has zero effect on the builder's profits. ${ }^{15}$

A second issue concerns the availability of land suitable for redevelopment: if no land exists that is close to satisfying the redevelopment rule in equation (3.1), then, even when $\delta$ is large, builders might not be able to earn excess profits from contemporaneous information about $\eta_{t}$. This would arise, for example, if all properties in the urban area had recently been redeveloped so that the existing stock of housing capital was too valuable to justify demolition (unless $\eta_{t}$ was especially large). In that case, however, no redevelopment would take place, and construction activity would be quite limited. For the market studied in this paper (single-family detached homes in Vancouver, B.C. during the 1980s), there was extensive redevelopment and construction every quarter. Such activity indicates that land suitable for development was available throughout the sample period and that builders, therefore, would likely profit from contemporaneous knowledge of $\eta_{t}$ given sufficiently high $\delta$.

\section{Quality Adjusted Building Prices}

Before discussing construction of the building price series and the empirical model to follow, it is necessary to first indicate the manner in which differences in quality across buildings are taken into account. Assume that all structural capital can be divided into equal homogenous units, and divide each building's price by its level of capital. Then,

$$
c_{t}=P_{t}^{B}(s(t-a)) / s_{t}(t-a), a \geq 0,
$$

\footnotetext{
${ }^{14}$ More generally, as construction lags diminish relative to the expected time before any mispricing of the development option is corrected, the effect of such mispricing on the builder's expected profits also diminishes. In the limit, as construction lags become arbitrarily short, mispricing of the development option completely differences out of the builder's profits.

${ }^{15}$ Mispricing of land for development could also arise because the existing structure was mispriced. However, urban theory predicts that only the oldest buildings in a neighborhood are redeveloped, and it seems unlikely that such buildings would be mispriced in a manner that would offset new building price shocks.
}

since $c_{t}$ is the unit price of capital. Dividing equation (3.3) by $s_{t}(t)$, substituting from equation (3.4), and manipulating gives

$$
q_{t}^{B}(s(t-a))=c_{t} \cdot\left[s_{t}(t-a) / s_{t}(t)\right]
$$

where $q_{t}^{B}(s(t-a))$ is the quality adjusted price of a "standard" vintage $t-a$ building at time $t$, and $s_{t}(t-a) / s_{t}(a)$ is the ratio of capital between an age- $a$ and a newly constructed $(a=0)$ standard building at $t .^{16}$

The quality — and therefore price — of a standard building built at $t-a$ relative to a new building is given by $s_{t}(t-a) /$ $s_{t}(a)$. In general, $s_{t}(t-a) / s_{t}(a)$ is less than 1 , causing $q_{t}^{B}(s(t-a))$ to be less than $q_{t}^{B}(s(t))$. This occurs for three reasons.

First, for a given building, housing capital physically depreciates over time. Second, assuming that vacant land and capital are substitutes in housing production and holding lot size fixed, in equilibrium an increase in the relative price of vacant land to capital - as occurs when cities grow over time - raises $s_{t}(a)$, the optimal level of capital in the standard building. Third, for older buildings $(a>0), s_{t}(t-a)$ likely falls with an increase in the current relative price of vacant land to capital. This occurs because the increase in $s_{t}(t)$ resulting from a rise in $P_{t}^{L} / c_{t}$ exaggerates the economic obsolescence of older buildings. That increased obsolescence accelerates the time to redevelopment for older structures which reduces $s_{t}(t-a)$.

Given these arguments, and dropping the $j$ subscripts for convenience, suppose that

$$
\begin{aligned}
\log \left[s_{t}(t-a) / s_{t}(t)\right]= & \theta_{1, a} \log \left(P_{t-a}^{L} / c_{t-a}\right) \\
& -\theta_{2, a} \log \left(P_{t}^{L} / c_{t}\right),
\end{aligned}
$$

where $\theta_{1, a}$ and $\theta_{2, a}$ are both positive, and, for newly constructed buildings $(a=0), \theta_{1, a}-\theta_{2, a}$ equals zero since $s_{t}(t-a) / s_{t}(t)$ equals $1 .{ }^{17}$ Taking logs of equation (3.5), substituting from equation (3.6), and rearranging gives

$$
\begin{aligned}
\log \left[q_{t}^{B}(s(t-a))\right]= & \log \left(c_{t}\right)+\theta_{1, a} \log \left(P_{t-a}^{L} / c_{t-a}\right) \\
& -\theta_{2, a} \log \left(P_{t}^{L} / c_{t}\right) .
\end{aligned}
$$

Equation (3.7) describes the long-run equilibrium determinants of the quality-adjusted price of a standard building and has important implications for the empirical work to follow. For new buildings, equation (3.7) reduces to $\log \left(c_{t}\right)$, where $\log \left(c_{t}\right)$ has a unit coefficient, which says that the qualityadjusted price of a newly constructed standard building is

\footnotetext{
${ }^{16}$ For the empirical work to follow, a standard building is defined as a given type of building, such as a single-family detached building with 2,000 sq. ft. of floor space, two bathrooms, and a garage.

${ }^{17}$ Suppose that $P_{t-a}^{L} / c_{t-a}$ is constant over time. Then equation (3.6) simplifies to $\left(\theta_{1, a}-\theta_{2, a}\right) P_{t}^{L} / c_{t}$, and it is clear that, with depreciation, $\left(\theta_{1, a}-\theta_{2, a}\right)$ must also be negative and increase in magnitude with the age of the building.
} 
determined solely by current construction costs. For older buildings $(a>0)$, the quality-adjusted price of a standard building varies with changes in the current cost of construction, as well as with changes in $P_{t-a}^{L} / c_{t-a}$ and $P_{t}^{L} / c_{t}$, where $t-a$ is the period in which the older building was constructed.

\section{Data and Construction of the Price Series}

\section{A. Data}

The principle data set is based on British Columbia Assessment Authority (BCAA) records of all single-family detached home sales that took place in ten neighborhoods in Vancouver, B.C., over the 1979 through 1989 period. For each sale, detailed information was available on the characteristics of the structure and lot. After dropping observations with missing values, 25,244 homes sales were retained for analysis.

A key feature of the data concerns the character of the ten neighborhoods. With one exception, the neighborhoods were contiguously aligned along a major east-west corridor in Vancouver. In addition, the neighborhoods were quite small in geographic scope, typically on the order of one square mile. Most important, the ten neighborhoods were chosen because locational amenities vary little within each neighborhood. In addition, within each neighborhood, there is little variation in the variety of housing types (quality) found on any given street. For these reasons, there is little correlation within neighborhoods between housing type and locational amenities. ${ }^{18}$ As discussed in the appendix, that feature of the data reduces possible omitted-variable bias problems and, under plausible conditions, ensures that the price series developed below will be unbiased and consistent.

\section{B. Construction of the Price Series}

To construct the price series for vacant land and buildings, a hedonic equation of house value was first estimated separately for each quarter from 1979:1 through 1989:4. For each regression, dummy variables were included for the ten neighborhoods $\left(L_{1}, L_{2}, \ldots, L_{10}\right)$. In addition, all of the structural attributes were interacted with vintage dummy variables corresponding to whether the building is five years old or less $\left(V^{\text {new }}\right)$, five to thirty years old $\left(V^{\text {mid }}\right)$, or older than thirty years $\left(V^{\text {old }}\right)$. Also, the coefficients on the structural attributes were not allowed to vary with location, and the regressions were estimated using a linear specification. ${ }^{19}$

\footnotetext{
${ }^{18}$ The above assessment of within-neighborhood spatial variation in locational amenities and housing types is based on close personal experience: I lived in one of the neighborhoods used in this paper from 1989 to 1992 and in a second neighborhood from 1992 to 1997. In addition, I have driven through the remaining neighborhoods in the data set innumerable times.

${ }^{19}$ The linear specification facilitates separation of house prices into their vacant land and building price components, while interacting the structural attributes with vintage dummy variables, including locational fixed effects,
}

The resulting hedonic regression is

$$
\begin{aligned}
P_{t_{j i}}^{D}= & \sum_{j=1}^{j=10} \gamma_{t_{j}} L_{t_{j i}}+\gamma_{t_{L S}} \text { LotSize }_{t_{j i}}+\gamma_{t_{C}} \text { Corner }_{t_{j i}} \\
& +\beta_{t}^{\text {new }} V_{t_{j i}}^{\text {new }} X_{t_{j i}}+\beta_{t}^{\text {mid }} V_{t_{j i}}^{\text {mid }} X_{t_{j i}} \\
& +\beta_{t}^{\text {old }} V_{t_{j i}}^{\text {old }} X_{t_{j i}}+\omega_{t_{j i}},
\end{aligned}
$$

where $P_{t_{j i}}^{D}$ is the price of the house (developed land) as before, LotSize is the square footage of the lot, Corner is a dummy variable for whether the property is on a corner lot ( 1 for yes), and $X$ is the vector of included structural attributes. The elements of $X$ include the square footage of the floor space, the number of rooms, dummy variables for whether there is a fireplace or a garage, and the building's age (AGE).

Given quarterly estimates of equation (4.1), the "standard" building and location were defined by the average values of the structural, lot size, corner dummy, and locational dummy variables over the eleven-year sample. ${ }^{20}$ Thus, the quality-adjusted (fixed-weight) price of an age- $a$ building, $q_{t}^{B}(s(t-a))$, is given by the terms, $\beta_{t}^{\text {new }} \bar{X}, \beta_{t}^{\text {mid }} \bar{X}$, and $\beta_{t}^{\text {old }} \bar{X}$, for new, middle-aged, and older buildings, respectively, where the overbar denotes the sample-wide average for $X$. Similarly, the quality-adjusted price of vacant land in quarter $t$ (denoted hereafter by $q_{t}^{L}$ ) is given by the sum $\sum \gamma_{t_{j}} \bar{L}_{j}+\gamma_{t_{L S}} \overline{\text { LotSize }}+\gamma_{t_{C}} \overline{\text { Corner. }}^{21}$

\section{Additional Data}

An annual construction cost index for Vancouver was also obtained from Canada Mortgage and Housing Corporation (CMHC). Quarterly estimates of construction cost were then obtained by linearly interpolating between annual observations. ${ }^{22}$ Finally, quarterly series for inflation, nominal long-

and estimating on a quarterly basis introduces tremendous flexibility into the functional form.

${ }^{20}$ The only exception was for AGE which was set to 35 for older buildings (AGE $>30), 25$ for middle-aged buildings $(5<\mathrm{AGE} \leq 30$ ), and 3 for new buildings (AGE $\leq 5$ ).

${ }^{21} \mathrm{~A}$ possible concern in constructing the price indexes is that equation (4.1) includes only a subset of the structural attributes while Corner is the only control for within neighborhood variation in locational amenities. Recall, however, that within-neighborhoods housing type and locational amenities are unlikely to be correlated for reasons outlined above. Moreover, as shown in the appendix, if the correlation between the omitted and included structural attributes is constant over time, quarterly estimates of equation (4.1) yield unbiased estimates of the building price series. Similarly, if the proportion of home sales in location $j$ and time $t$ is constant over time, the vacant land price series will also be unbiased and consistent. As a robustness check, an alternate vacant land price series was constructed based on a sample of homes that likely sold for redevelopment, since such homes sell for the price of vacant land as in section III (e.g., Rosenthal \& Helsley, 1994). Findings indicate that the alternative vacant land price series is highly positively correlated with the principal series developed in the text. Details are in the appendix.

${ }^{22}$ Although this interpolation procedure smooths the quarterly variation in construction costs, as will become apparent, for several periods over the 1980 s, quarterly variation in the price of new buildings far exceeds anything that could be attributed to short-term fluctuations in construction 
Figure 1.-New House, New Building, And Land Prices Versus CONSTRUCTION Costs

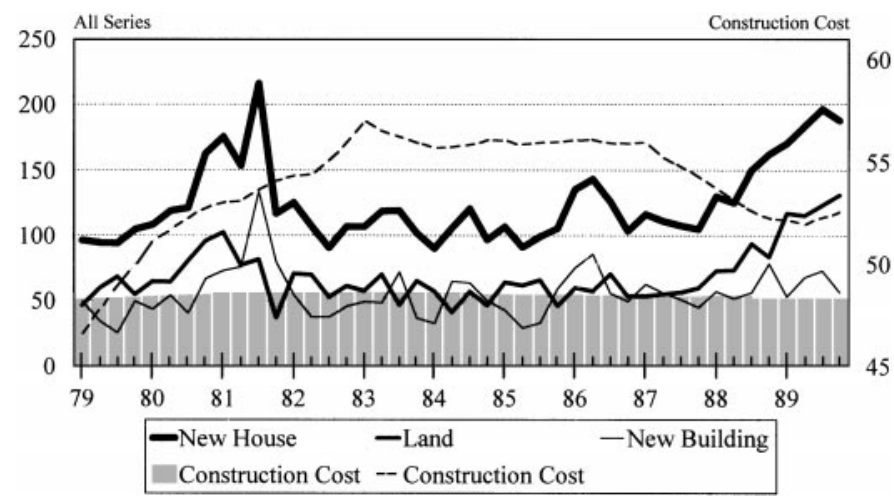

Construction costs are normalized to the median of the building price series. (All variables are in 1979:1 $\$ 1,000$ units.)

Table 1.-Selected Summary Statistics

\begin{tabular}{lcccccc}
\hline \hline & $\begin{array}{c}\text { New } \\
\text { House }\end{array}$ & $\begin{array}{c}\text { Vacant } \\
\text { Land }\end{array}$ & $\begin{array}{c}\text { New } \\
\text { Bldg }\end{array}$ & $\begin{array}{c}\text { Age-25 } \\
\text { Bldg }\end{array}$ & $\begin{array}{c}\text { Age-35 } \\
\text { Bldg }\end{array}$ & $\begin{array}{c}\text { Constr. } \\
\text { Cost }\end{array}$ \\
\hline Mean & 125.27 & 69.29 & 55.98 & 35.95 & 27.55 & 53.92 \\
Median & 116.72 & 64.29 & 53.92 & 34.22 & 26.15 & 54.36 \\
Std. Dev & 31.542 & 21.81 & 18.96 & 14.78 & 12.44 & 2.427 \\
\hline Note: Sample Period: $1979: 1$ to $1989 \cdot 4$ (all values are in 1979:1 $\$ 1,000$ units).
\end{tabular}

term interest rates, and various indicators of building activity in Vancouver were used in certain parts of the analysis below. These series were obtained from the CANSIM database provided by Statistics Canada.

\section{Building Prices and Construction Costs in an Error-Correction Model}

\section{A. A Preliminary View of the Series}

Figure 1 displays the quality-adjusted prices for newly constructed homes and buildings, as well as the qualityadjusted price for vacant land over the sample period. (All series are in levels.) Also shown by both the gray bars (on the left vertical axis) and the dotted line (on the right vertical axis) is the construction cost index, where the index has been normalized to the median of the new building price series. All series are in 1979:1, \$1,000 units, both for figure 1 and for the remaining figures and tables in the paper. Selected summary statistics are provided in table 1 .

Immediately apparent from figure 1 is that both the vacant land and building price series rose sharply around 1981 and then fell precipitously in the following year. For the purposes of this paper, a possible concern is whether the dramatic episode of price volatility in 1981 represents an unmodeled phenomena that could bias estimates from the time-series analysis to follow. ${ }^{23}$ For that reason, all of the

costs. Note, also, that both Rosen (1979) and Somerville (1994) find that construction costs vary seasonally, but by amounts that are far less than the quarterly fluctuation in building prices found in the data here.

${ }^{23}$ Previous analysis by Clayton (1994) failed to establish why Vancouver house prices were so volatile in 1981. Note, however, that the focus of this study is not on why price shocks occur, but on whether prices subsequently
Figure 2.-R-SQUAREd From the QuARTERLy Hedonic REgRESSIONS

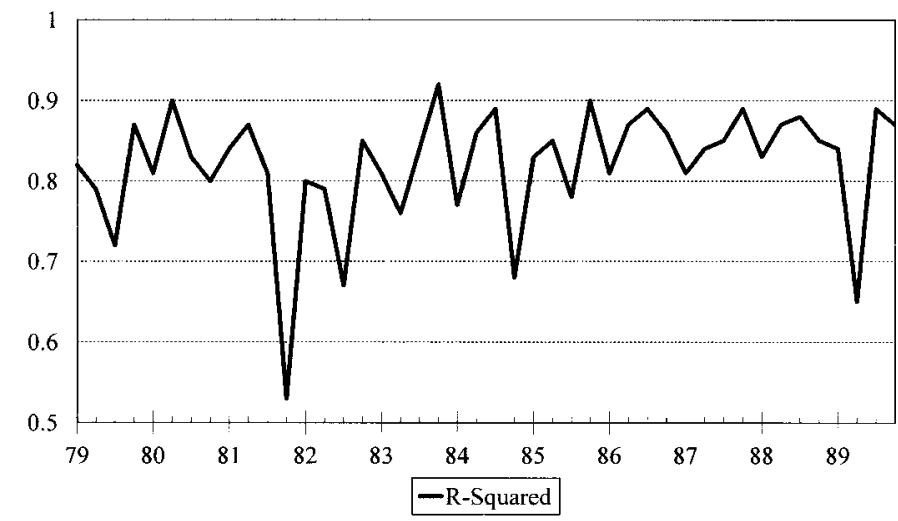

$($ Median $=0.84$, Mean $=0.82)$

empirical analysis is executed twice: first for the full time series from 1979:1 to 1989:4, and then again from 1982:1 to 1989:4. As will become apparent, results from the two sample periods are similar, which suggests that the findings from this study are robust to the price volatility in $1981 .^{24}$

In figure 2 , observe that the median $R^{2}$ statistic for the quarterly hedonic regressions is $84 \%$, which suggests that both the hedonic equations and the price indices are estimated with considerable precision. ${ }^{25}$ Indeed, figure 3 displays the $95 \%$ confidence interval around the new building price series in addition to construction costs: in general, the confidence interval is quite narrow. Moreover, upon review of figure 3 , it is hard to avoid drawing the following conclusions: new building prices significantly deviated from construction costs several times over the sample period; new building prices follow construction costs quite closely over the long run; and deviations between new building prices and construction costs are corrected quite rapidly.

\section{B. Unit Root Tests and Stationarity of the Series}

Before proceeding with a more careful analysis of the relationships above, it is desirable to address the order of integration (differencing) that will render the series stationary. ${ }^{26}$ Also, because equation (3.7) is in logs, hereafter all variables are interpreted in logs unless noted. With that in mind, Augmented Dickey Fuller (ADF) tests were used to test for unit roots in the series that appear in the tables to

return to their long-run values with sufficient speed as to preclude arbitrage opportunities.

${ }^{24}$ Observe that figure 1 also shows that vacant land and new building prices provide approximately equal shares of house value over much of the sample period. Thus, deviations between new building prices and construction costs could have a substantial effect on the overall price of housing.

25 The high precision reflects the small geographic scope of the neighborhoods coupled with the inclusion of locational fixed effects and an extensive set of structural attributes in the hedonic regressions.

${ }^{26}$ As is well established, regressing one nonstationary series on another typically yields biased estimates, while inference is generally not possible because the variance of a nonstationary series increases without bound over time. 
Figure 3.-95\% Confidence Interval for New Building Prices Versus CONSTRUCTION COSTS

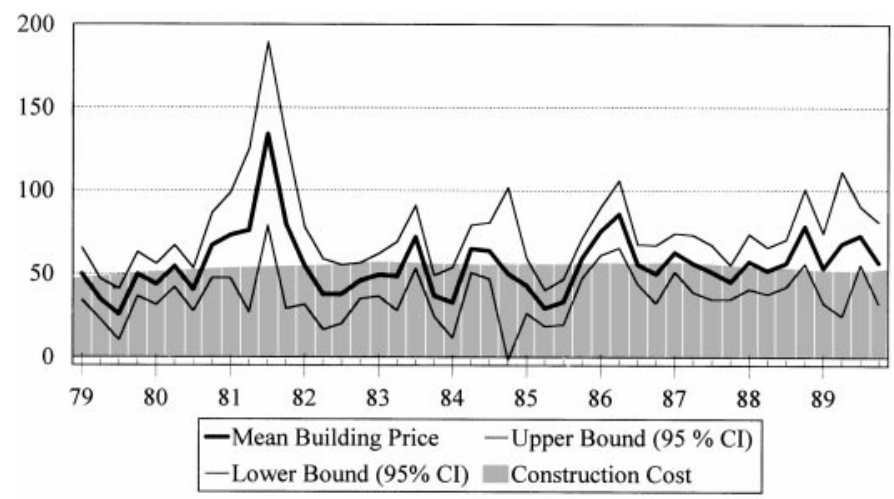

Construction costs are normalized to the median of the building price series

TABLe 2.-ADF Unit Root Tests On Log-Levels: SAMPLE PERIOD: 1979:1 TO 1989:4

\begin{tabular}{cccclc}
\hline \hline Variable & ADF Stat & Variable & ADF Stat & Variable & ADF Stat \\
\hline$q_{t .5}^{\mathrm{B}}$ & -2.781 & $c_{t}$ & -1.766 & Start $_{t}$ & -3.147 \\
$q_{t, 25}^{\mathrm{B}}$ & -3.014 & $q_{t}^{\mathrm{L}} / c_{t}$ & -0.228 & $\mathrm{r}_{\mathrm{t}}$ & -3.038 \\
$q_{\mathrm{t}, 35}^{\mathrm{B}}$ & -2.972 & $q_{t, 5}^{\mathrm{B}} / c_{t}$ & -2.574 & $(r-\pi)_{t}$ & -1.743 \\
$q_{t}^{\mathrm{L}}$ & -0.585 & Perm $_{t}$ & -3.135 & $H_{\text {inv, },}$ & -4.899 \\
\hline
\end{tabular}

Notes: Tests include a constant, trend, and four lags of the dependent variable except for $q_{5}^{\mathrm{B}} / c_{t}$, for which the MacKinnon (1991) critical values were $1 \%:-4.209 ; 5 \%$ : -3.528 ; and $10 \%:-3.387$. For $q_{t, 5}^{\mathrm{B}} / c_{\text {, }}$ , the constant and trend terms were omitted consistent with the theoretical arguments from section III. In that case, the corresponding critical values were $1 \%$ : -2.623 and $5 \%$ : -1.950 .

follow. Results from those tests are in table 2. For each test, four quarterly lags of the dependent variable were included in order to whiten the residuals. Also, unless noted, the ADF tests included a constant and a trend term to allow for both drift and a deterministic trend. Finally, all of the ADF tests used the full time series (1979:1 to 1989:4) to increase the power of the tests. ${ }^{27}$

In table 2, observe that nearly all of the series display unit roots in log levels based on the ADF tests. ${ }^{28}$ The principal exception is the deviation between new building prices and construction costs, $q_{t, 5}^{B} / c_{t}$, which appears to be $\mathrm{I}(0)$. To better understand these results, note that $c_{t}$ is driven by the cost of materials and labor. Assuming that materials prices have trended upwards over time in a random manner as quality lumber and other building materials have become more scarce, then, with rising real wages, $c_{t}$ could be I(1). If $c_{t}$ is

\footnotetext{
${ }^{27}$ In viewing the ADF tests, a strong caveat should be considered. Cochrane (1991) has shown that the power of unit root tests (not just the ADF test) is quite low in small samples such as the one here. Similarly, Faust (1993) has shown that, for finite samples, it is not possible to distinguish between a unit root process and a highly persistent trend stationary process. As such, a critic of ADF tests could argue that the most prudent course here is to rely on economic theory to impose assumptions regarding the stationarity of the relevant variables. Nevertheless, given the almost universal convention of pretesting time-series data for stationarity, the ADF tests are presented. As will become apparent, economic arguments are consistent with several of the results from the ADF tests.

${ }^{28}$ These findings are consistent with those of Clayton (1994), who also reports test results indicating that many real estate price series in Vancouver, B.C., are nonstationary in levels but stationary in first differences.
}

$\mathrm{I}(1)$, given previous arguments that $q_{t, 5}^{B}$ is equal to $c_{t}$ in the long run, $q_{t, 5}^{B}$ should also be $\mathrm{I}(1)$ and $q_{t, 5}^{B} / c_{t}$ should be $\mathrm{I}(0)$. Similarly, population growth, extensive residential zoning, and the fact that Vancouver is built on two "fully developed" peninsulas would likely cause real (vacant) land prices to trend upwards over time in a potentially random manner. Under those conditions, $q_{t}^{L}$ could be I(1) as well. Since older building prices depend on both construction costs and vacant land prices in the long run (see section III), if both $c_{t}$ and $q_{t}^{L}$ are nonstationary, $q_{t, 25}^{B}$ and $q_{t, 35}^{B}$ should also be nonstationary. Accordingly, the analysis below assumes that all of the principle series are I(1).

\section{An ECM of Building Prices and Construction Costs}

In expression (3.7), the quality-adjusted price of a standard age- $a$ building, $q_{t, a}^{B}$ depends on three variables: the relative price of vacant land to capital in both the current period and at the time of construction, $q_{t}^{L} / c_{t}$ and $q_{t-a}^{L} / c_{t-a}$, respectively, and the current cost of construction, $c_{t}$. Data on $c_{t}$ and $q_{t}^{L}$ are available as previously described. However, data on $q_{t-a}^{L} / c_{t-a}$ are not available for age-25 and age-35 building prices since that would require information on $q_{t-a}^{L}$ ' $c_{t-a}$ from 1945 to 1965 given that our sample of "current" prices runs from 1979 through 1989. To address that limitation, it is assumed that $q_{t-a}^{L} / c_{t-a}$ was constant over the 1945 to 1965 period. Expression (3.7) can then be rewritten as $^{29}$

$$
q_{t, a}^{B}=\alpha_{0, a}+\alpha_{1, a} c_{t}+\alpha_{2, a}\left(q_{t}^{L} / c_{t}\right)+e_{t, a}
$$

where $a=5,25$, and 35 denotes new, middle-aged, and older buildings, respectively.

Expression (5.1) is the single (theoretical) cointegrating equation that governs the long-run equilibrium relationship between the quality-adjusted price of a standard building, the current cost of construction, and the current relative cost of vacant land to capital. ${ }^{30}$ Recall from equation (3.7) that the long-run price of a newly constructed building equals $c_{t}$. Thus, for new buildings $\alpha_{0, a}$ and $\alpha_{2, a}$ equal zero, while $\alpha_{1, a}$ equals 1 . For older buildings $\alpha_{1, a}$ should also equal 1 , but $\alpha_{0, a}$ typically differs from zero, and its sign is equal to the sign of $q_{t-a}^{L} d c_{t-a}$ (in logs), while $\alpha_{2, a}$ is negative because an increase in the current relative cost of vacant land to capital raises the relative quality (and price) of a new standard building as compared to an older building.

\footnotetext{
${ }^{29}$ The models below were also estimated including a deterministic trend in equation (5.1) and a constant in the error correction equations equation (5.2) to follow. In all cases, the trend and constant terms were close to zero and did not affect the results. For that reason, the trend term is omitted from equation (5.1), as is the constant from equation (5.2).

${ }^{30}$ With three endogenous variables, $q_{t, a}^{B}, c_{t}$, and $q_{t}^{L} / c_{t}$, in principle there could be up to two cointegrating vectors. In practice, however, the theoretical arguments from section III, in conjunction with the assumption that $c_{t}$ is strictly exogenous, suggest that equation (5.1) is the only cointegrating equation.
} 
The error correction equation corresponding to equation (5.1) is given by ${ }^{31}$

$$
\begin{aligned}
\Delta q_{t, a}^{B}= & \delta_{a} e_{t-1, a}+\sum_{l=1}^{4} a_{B_{1, a}} \Delta q_{t-1, a}^{B}+\sum_{l=1}^{4} a_{c_{1, a}} \Delta c_{t-l} \\
& +\sum_{l=1}^{4} a_{L_{l, a}} \Delta\left(q_{t-l}^{L} / c_{t-l}\right)+\epsilon_{t, a}, \\
a= & 5,25,35,
\end{aligned}
$$

where $\Delta q_{t, a}^{B}$ (with $q_{t, a}^{B}$ in logs) is the quarterly growth rate of vintage $t-a$ building prices. Observe that the one-period lag of the error term from equation (5.1), $e_{t-1, a}$, is included as a regressor in (5.2). Given that equation (5.1) describes a long-run equilibrium relationship, $e_{t, a}$ can be interpreted as a short-run shock to the price of an age- $a$ building in period $t$, the effect of which should dissipate over time, provided that $q_{t, a}^{B}$ is indeed cointegrated with $c_{t}$ and $q_{t}^{L} / c_{t}$. For that reason, $e_{t, a}$ is typically referred to as the error-correction term and, since the dependent variable in equation (5.2) is the rate at which building prices change, $\delta_{a}$ measures the speed with which $q_{t, a}^{B}$ converges back to its long-run equilibrium value following a shock. Finally, note that, for the older buildings, four quarterly lags of the three endogenous variables $\left(\Delta q_{t, a}^{B}\right.$, $\Delta c_{t}$, and $\left.\Delta\left(q_{t}^{L} / c_{t}\right)\right)$ are included in equation (5.2) to control for serial correlation arising from the short-run dynamics. In contrast, only lags of $\Delta q_{t, a}^{B}$ and $\Delta c_{t}$ are included for new buildings since $q_{t}^{L} / c_{t}$ does not enter equation (5.1) for $a=0$.

Expression (5.1) was stacked for the three building price series and estimated by seemingly unrelated regression (SUR) imposing the restrictions that $\alpha_{0,5}=\alpha_{2,5}=0$ for new buildings, and the cross equation restriction that $\alpha_{1, a}$ is alike for all vintage buildings given the strong theoretical priors for those parameters. Similarly, equation (5.2) was stacked for the three building price series and estimated by SUR omitting the lagged $\Delta\left(q_{t}^{L} / c_{t}\right)$ terms for new buildings for reasons described above. ${ }^{32}$ This is the Engle-Granger (1987) two-step method for estimating an ECM, where SUR is used here at each stage to enhance efficiency relative to OLS. As shown by Stock (1987), coefficient estimates from the first-stage cointegrating equation converge at rate $T$ and are "superconsistent," while coefficient estimates from the second-stage error-correction equation converge at the more usual rate $T^{1 / 2}$. Moreover, the standard errors from the second-stage equation have a standard limiting distribution enabling one to interpret the $t$-ratios in the usual manner. ${ }^{33}$

\footnotetext{
${ }^{31}$ Although analogous expressions can be written with construction costs and the price of vacant land as the dependent variable, those equations are not presented in order to focus on building prices.

32 The model was estimated relaxing these restrictions. While the estimated coefficient on $c_{t}$ differed somewhat in expression (5.1) for older buildings, the basic results were essentially the same for both expression (5.1) and (5.2).

${ }^{33}$ The ECM was also estimated using the Johansen (1991) method. For new buildings, all results were quite similar to those obtained with the Engle-Granger two-step method. For older buildings, the estimated cointegrating equations differed somewhat from the two-step results, but the error-correction equations were little changed. Overall, the Engle-
}

In contrast, standard errors from the first-stage cointegrating equation as obtained from the Engle-Granger two-step method have a nonstandard limiting distribution. Accordingly, a third-stage OLS equation was estimated to "update" the first-stage coefficient estimates and to correct the standard errors as described by Engle and Yoo (1991), allowing one to conduct inference for the cointegrating equation. ${ }^{34}$

\section{Principal Empirical Results}

\section{A. The Cointegrating Equations}

Table 3 presents SUR estimates of the cointegrating equations corresponding to expression (5.1) for both the full sample (1979:1 to 1989:4) and for the restricted sample (1982:1 to 1989:4). Observe that the estimates are quite similar for the two different sample periods, which suggests that the findings are robust to the volatile period in 1981 documented earlier. Focusing on the full-sample estimates, to formally test the hypothesis that expression (5.1) is the cointegrating equation, $\mathrm{ADF}$ tests were used to examine the residuals from the cointegrating equations for each vintage building. Results reject the null of a unit root in the corresponding error terms in each case. ${ }^{35}$ Thus, the data support the hypothesis that expression (5.1) is the cointegrating equation that governs both new and old building prices in long-run equilibrium. Observe, also, that the coefficient on $c_{t}$ is virtually equal to 1 and highly significant, consistent with the most important theoretical prediction from section III. Similarly, for older buildings, the coefficients on $q_{t}^{L} / c_{t}$ are negative and significant as expected.

\section{B. The Speed of Adjustment}

Table 4 presents estimates of the error-correction equations for each of the three vintage buildings for both the full (1979:1 to 1989:4) and restricted (1982:1 to 1989:4) sample periods. ${ }^{36}$ Estimates of the speed of convergence $\left(\delta_{a}\right)$ are quite similar for new buildings in both sample periods, but somewhat faster for older buildings in the restricted-sample

Granger two-step method was preferred given recent evidence that the Johansen method, while consistent, can suffer from substantial smallsample bias (e.g., Gregory, 1994).

${ }^{34}$ In the third stage, residuals from the error-correction equation (5.2) were regressed on lagged values of the I(1) regressors in the cointegrating equation, where the regressors were first scaled by $\delta$, the coefficient on $e_{t, a}$ in equation (5.2). Engle and Yoo (1991) show that one can approximate FIML estimates of the coefficients in the cointegrating equation by adding the estimated coefficients from the first- and third-stage equations. Also, the standard errors from the third-stage equation have a standard limiting distribution and are consistent estimates of the true standard errors for the FIML coefficients. Thus, one can calculate $t$-ratios for the cointegrating equation using the third-stage standard errors and conduct inference in the usual way.

${ }^{35}$ The ADF test statistics (including four lags of the dependent variable but no constant or trend) for new, age-25, and age-35 buildings were $-2.55,-2.60$, and -2.47 , respectively. By comparison, the critical values at the $1 \% 5 \%$ levels were -2.62 and -1.95 , respectively.

${ }^{36}$ The residuals from the error-correction equations showed little evidence of serial correlation (based on the correlogram), while the Jarque-Bera test could not reject the null that the residuals were normally distributed. 


\begin{tabular}{|c|c|c|c|c|c|c|}
\hline & \multicolumn{3}{|c|}{ Full Sample: 1979:1 to 1989:4 } & \multicolumn{3}{|c|}{ Constrained Sample: 1982:1 to 1989:4 } \\
\hline & New Bldngs & Age-25 & Age -35 & New Bldngs & Age-25 & Age-35 \\
\hline Constant & - & -0.4065 & -0.6391 & - & -0.4511 & -0.6736 \\
\hline$\left(\alpha_{0}\right)$ & - & $(-7.933)$ & $(-9.872)$ & - & $(-8.101)$ & $(-10.23)$ \\
\hline$c_{t}$ & 1.002 & 1.002 & 1.002 & 0.9879 & 0.9879 & 0.9879 \\
\hline$\left(\alpha_{1}\right)$ & $(84.31)$ & $(84.31)$ & $(84.31)$ & $(113.5)$ & $(113.5)$ & $(113.5)$ \\
\hline$q_{t}^{\mathrm{L}} / c_{t}$ & - & -0.2828 & -0.6177 & - & -0.1949 & -0.7234 \\
\hline$\left(\alpha_{2}\right)$ & - & $(-1.704)$ & $(-2.937)$ & - & $(-1.511)$ & (3.896) \\
\hline $\mathrm{ADF}$ Stat $^{a}$ & -2.55 & -2.60 & -2.47 & - & - & - \\
\hline
\end{tabular}

Table 4.-SUR Estimates of the Error Correction Equation for the Price OF QuALITY-AdJusted BuILDINGS

\begin{tabular}{|c|c|c|c|c|c|c|}
\hline & \multicolumn{6}{|c|}{ FULL SAMPLE 1979:1 TO 1989:4 } \\
\hline & \multicolumn{2}{|c|}{ New Buildings } & \multicolumn{2}{|c|}{25 Year Old Buildings } & \multicolumn{2}{|c|}{35 Year Old Buildings } \\
\hline & Coeff & $t$-ratio & Coeff & $t$-ratio & Coeff & $t$-ratio \\
\hline$e_{t-1}$ & -0.7885 & -3.5545 & -0.6703 & -4.2646 & -0.6977 & -3.8820 \\
\hline$\Delta q_{t-1}^{\mathrm{B}}$ & 0.2371 & 1.2315 & -0.4602 & -2.8791 & -0.3256 & -1.8082 \\
\hline$\Delta q_{t-2}^{\mathrm{B}}$ & 0.1125 & 0.6565 & -0.2868 & -1.7747 & -0.4370 & -2.5412 \\
\hline$\Delta q_{t-3}^{\mathrm{B}}$ & 0.2062 & 1.3554 & 0.1919 & 1.4108 & -0.0949 & -0.5934 \\
\hline$\Delta q_{t-4}^{\mathrm{B}}$ & -0.0181 & -0.1314 & 0.2801 & 2.2332 & 0.0099 & 0.0701 \\
\hline$\Delta c_{t-1}$ & 1.1621 & 0.1570 & 0.1518 & 0.6469 & 0.5888 & 1.9357 \\
\hline$\Delta c_{t-2}$ & 3.1871 & 0.3855 & -0.1089 & -0.4391 & -0.3402 & -1.0592 \\
\hline$\Delta c_{t-3}$ & -5.1748 & -0.6265 & 0.5392 & 2.1740 & 0.2259 & 0.6815 \\
\hline$\Delta c_{t-4}$ & 0.3381 & 0.0508 & 0.8010 & 3.1999 & 0.4619 & 1.4307 \\
\hline$\Delta\left(q_{t-1}^{\mathrm{L}} / c_{t-1}\right)$ & - & - & -3.9216 & -0.4687 & -5.5317 & -0.4693 \\
\hline$\Delta\left(q_{t-2}^{\mathrm{L}} / c_{t-2}\right)$ & - & - & 0.0766 & 0.0081 & -2.0749 & -0.1560 \\
\hline$\Delta\left(q_{t-3}^{\mathrm{L}} / c_{t-3}\right)$ & - & - & -1.6194 & -0.1720 & 1.8399 & 0.1403 \\
\hline$\Delta\left(q_{t-4}^{\mathrm{L}} / c_{t-4}\right)$ & - & - & 12.006 & 1.6126 & 17.972 & 1.7193 \\
\hline Sample Size & \multicolumn{2}{|c|}{39} & \multicolumn{2}{|c|}{39} & \multicolumn{2}{|c|}{39} \\
\hline $\mathrm{R}^{2}$ & \multicolumn{2}{|c|}{0.224} & \multicolumn{2}{|c|}{0.296} & \multicolumn{2}{|c|}{0.065} \\
\hline $\mathrm{R}^{2}$-Adj & \multicolumn{2}{|c|}{0.017} & \multicolumn{2}{|c|}{0.000} & \multicolumn{2}{|c|}{0.000} \\
\hline$\sigma$ & \multicolumn{2}{|c|}{0.302} & \multicolumn{2}{|c|}{0.364} & \multicolumn{2}{|c|}{0.501} \\
\hline SSR & \multicolumn{2}{|c|}{2.734} & \multicolumn{2}{|c|}{3.261} & \multicolumn{2}{|c|}{6.515} \\
\hline DW & \multicolumn{2}{|c|}{1.703} & \multicolumn{2}{|c|}{1.969} & \multicolumn{2}{|c|}{1.707} \\
\hline $\mathrm{Q}(5)$ & \multicolumn{2}{|c|}{2.194} & \multicolumn{2}{|c|}{1.434} & \multicolumn{2}{|c|}{2.169} \\
\hline $\mathrm{Q}(10)$ & \multicolumn{2}{|c|}{4.795} & \multicolumn{2}{|c|}{6.766} & \multicolumn{2}{|c|}{11.15} \\
\hline \multicolumn{7}{|c|}{ RESTRICTED SAMPLE 1982:1 TO 1989:4ª } \\
\hline$e_{t-1}$ & -0.7647 & -3.672 & -0.8607 & -4.171 & -0.9117 & -3.907 \\
\hline Sample Size & 31 & & 3 & & & \\
\hline $\mathrm{R}^{2}$ & & & & & & \\
\hline $\mathrm{R}^{2}$-Adj & & & & & & \\
\hline$\sigma$ & & & & & & \\
\hline SSR & & & & & & \\
\hline DW & & & & & & \\
\hline $\mathrm{Q}(5)$ & & & & & & \\
\hline $\mathrm{Q}(10)$ & & & & & & \\
\hline
\end{tabular}

Note: ${ }^{a}$ Lagged terms are not presented to conserve space.

period. Overall, however, as for the cointegrating equations, the qualitative nature of the findings do not appear to be sensitive to the price volatility in 1981 . For that reason, the remaining discussion is based on the full sample to take advantage of the longer time series. ${ }^{37}$

\footnotetext{
37 The ECM was reestimated several times, including deterministic trends in the cointegrating equations for the older building prices, as well as splitting $q_{t}^{L} / c_{t}$ (in logs) into $q_{t}^{L}$ and $c_{t}$. In all cases, the qualitative (and, in most cases, quantitative) nature of the results from the error-correction equations was similar to table 4 .
}

Observe that the $\delta_{a}$ coefficients on the error correction term, $e_{t-1, a}$, equal $-0.789,-0.670$, and -0.698 , for new, age- 25 , and age- 35 buildings, respectively. Also, all of these estimates are highly significant with $t$-ratios above $3.5 .{ }^{38} \mathrm{In}$ addition, a Wald test fails to reject the null that the price of different vintage buildings converge at a similar rate (i.e.,

\footnotetext{
${ }^{38}$ This result further supports the underlying theory because, if $q_{t, a}^{B}, c_{t}$, and $q_{t}^{L} / c_{t}$ are cointegrated, at least one error-correction term from the overall system must be significant (e.g., Engle \& Granger, 1987).
} 
that $\delta_{5}=\delta_{25}=\delta_{35}$ ). ${ }^{39}$ As argued in the introduction, evidence that $\delta_{5}=\delta_{25}=\delta_{35}$ is consistent with the joint hypothesis that investors view new and existing buildings as close substitutes and that different vintage buildings yield equal expected risk-adjusted rates of return.

Consider now that, for new buildings, $96 \%$ of the short-run shock to the quality-adjusted price of a standard building disappears within two quarters (79\% after one quarter), while, for older buildings, roughly $90 \%$ of a short-run price shock is corrected within two quarters (69\% after one quarter). In contrast, in a recent paper testing the present-value relationship between house prices and rents (where house refers to the vacant land plus the building), Meese and Wallace (1993) find that quality-adjusted house prices converge back to long-run equilibrium (fundamental) values at a rate of $15 \%$ per quarter. ${ }^{40}$ Thus, the rate of convergence found here appears to be extremely rapid relative to house prices overall. What is as yet unclear, however, is whether builders nevertheless adjust housing starts in response to new building price shocks, and how the speed of convergence of new building prices compares to construction lags. ${ }^{41}$

\section{Short Run Shocks and Construction Activity}

To evaluate the impact of new building price shocks on construction activity, consider that the current level of housing starts $\left(S T R T_{t}\right)$ is a function of the information set at time $t\left(\Omega_{t}\right)$. Similarly, the one-period-ahead intended level of

\footnotetext{
39 The corresponding chi-square test statistic equaled 0.79 compared to a critical value of 5.99 at the $5 \%$ level. Also, when the $\delta_{a}$ coefficients were constrained to be alike for all vintage buildings, $\delta$ equaled -0.70 .

${ }^{40}$ The house price convergence rate of Meese and Wallace (1993) is the only such estimate of house price convergence rates that I am aware of. In principle, it would be interesting to develop a similar estimate using Vancouver house price data to provide a closer comparison to the building price convergence rates reported above. In practice, that would require that one collect data on house rents which would then be used to test the present-value relationship between house price and the fundamental value of the housing asset (as in Meese and Wallace (1994)). Such an endeavor, however, would be beyond the scope of this paper and would also suffer from the critique of Flood and Hodrick (1994) discussed earlier.

${ }^{41} \mathrm{~A}$ final point concerning the ECM is that $e_{t-1}$ can be expressed as $e_{t-1}=m_{t-1}+w_{t-1}$, where $m_{t-1}$ is measurement error equal to the deviation between the estimated building price and its true value, and $w_{t-1}$ is the economic shock. Given the discussion in section IV and the fact that the hedonic equation is estimated on a quarterly basis, $m_{t-1}$ likely has mean zero and is serially uncorrelated. Then on average the effect of $m_{t}$ on the estimated building price in period $t$ will be fully offset over the next period, biasing estimates of $\delta_{a}$ towards 1 . Recall from figures 2 and 3, however, that the hedonic equations and subsequent price indices are estimated with considerable precision, which greatly reduces concerns about measurement error. Moreover, the ECM was reestimated twice, downweighting information from the "noisy" quarters in each case. If measurement error is a serious problem, downweighting the noisy quarters should reduce estimates of $\delta_{a}$ relative to table 4 . Bearing that point in mind, in the first case, the data were weighted by $n_{t}^{-1 / 2}$, where $n_{t}$ is the number of home sales in quarter $t$. In the second case, the data were weighted by $1 /[10 \cdot(1-$ $\left.R_{t}^{2}\right)$ ], where $R_{t}^{2}$ is the goodness-of-fit for the period- $t$ hedonic regression as in figure 2 . In each case, estimates of the cointegrating equations were close to those in table 3 , while building prices converged at a slightly faster rate relative to table 4 . Given that weighting the data affects the information used to estimate the model, it is possible for the estimated rates of price convergence to increase upon downweighting the noisy quarters provided that measurement error is relatively small. Thus, the results of this study appear to be robust to measurement error.
}

housing starts for period $t$ is a function of the information set at time $t-1$. Letting the information set in period $t$ be given by $\Omega_{t} \equiv \Omega_{t-1}+\left(\Omega_{t}-\Omega_{t-1}\right)$, housing starts in $t$ can be written as

$$
\operatorname{STRT}_{t}=g\left(\Omega_{t-1}\right)+f\left(\Omega_{t}-\Omega_{t-1}\right) .
$$

Expression (6.1) is an identity that states that period- $t$ housing starts equal the intended level of starts in $t-1, g\left(\Omega_{t-1}\right)$, adjusted for new information in period $t, f\left(\Omega_{t}-\Omega_{t-1}\right)$.

Given that the focus here is on the extent to which deviations between new building prices and construction costs affect construction activity, it is desirable to clarify the impact of $e_{t, 5}$ on $f\left(\Omega_{t}-\Omega_{t-1}\right)$. In that regard, estimating equation (6.1) is simplified considerably by recognizing that lagged housing permits provide a direct measure of intended period- $t$ construction activity as of $t-1$ and, therefore, can be used to control for $g\left(\Omega_{t-1}\right)$. Current period housing supply variables can then be used to measure $f\left(\Omega_{t}-\Omega_{t-1}\right)$, the adjustment to period- $t$ housing starts for new information in $t .^{42}$ Thus, a regression of housing starts on lagged permits and current-period variables enables one to measure the extent to which different types of new information affect construction. Accordingly, the following equation was estimated:

$$
\begin{aligned}
\Delta \operatorname{STRT}_{t}= & \gamma_{e} \Delta e_{t, 5}+\gamma_{L} \Delta q_{t}^{L}+\gamma_{(r-\pi)} \Delta(r-\pi)_{t} \\
& +\gamma_{r} \Delta r_{t}+\gamma_{h_{i n v}} \Delta H_{i n v, t} \\
& +\sum_{l=1}^{4} \gamma_{p e r m, l} \Delta \operatorname{PERM}_{t-1} \\
& +\sum_{l=1}^{4} \gamma_{s t r t, l} \Delta S T R T_{t-1} \\
& +\sum_{l=1}^{4} Q_{l, t}+\gamma_{t} t+u_{t},
\end{aligned}
$$

where all variables other than $e_{t, 5}$ are in log-first differences, given that ADF tests (reported in table 2) suggest that all of the (log) variables in equation (6.2) are I(1) except for the new building price shock.

The most important current-period variable in equation (6.2) is, of course, the new building price shock, $e_{t, 5}$. In addition, controls are provided for the price of vacant land, $q_{t}^{L}$; real and nominal interest rates, $(r-\pi)_{t}$ and $r_{t}$, respectively (where $\pi$ is the inflation rate); and the level of completed but unsold residential buildings (inventories), $H_{i n v, t}$. Four quarterly lags of permits (PERM) are included to control for building plans prior to period $t$. Seasonal dummies, $Q_{l, t}(l=1, \ldots, 4)$, and a time trend, $t$, are included to control for deterministic seasonality and trends, and four quarterly lags of starts (STRT) are included to control for serial correlation. ${ }^{43}$

\footnotetext{
${ }^{42}$ Choice of period- $t$ variables was based on the housing supply study by DiPasquale and Wheaton (1994).

${ }^{43}$ Results were essentially unchanged when the lagged $S T R T$ variables were omitted.
} 


\begin{tabular}{|c|c|c|c|c|}
\hline & \multicolumn{2}{|c|}{$\begin{array}{c}\text { Full Sample } \\
\text { 1979:1 to 1989:4 }\end{array}$} & \multicolumn{2}{|c|}{$\begin{array}{c}\text { Restricted Sample } \\
\text { 1979:1 to 1989:4 }\end{array}$} \\
\hline & Coeff & $t$-ratio & Coeff & $t$-ratio \\
\hline$\Delta e_{t, 5}$ & -0.0705 & -0.6640 & 0.1076 & 0.4943 \\
\hline$\Delta q_{t}^{L}$ & 0.0212 & 0.1270 & 0.5820 & 1.6487 \\
\hline$\Delta r_{t}$ & -0.1127 & -3.9208 & -0.0620 & -0.8468 \\
\hline$\Delta(r-\pi)_{t}$ & 0.0040 & 0.3375 & 0.0210 & 1.0767 \\
\hline$\Delta H_{i n v, t}$ & -0.2221 & -1.5509 & -0.2942 & -1.1495 \\
\hline$\Delta$ Perm $_{t-1}$ & 0.7237 & 7.4418 & 1.0026 & 4.1887 \\
\hline$\Delta$ Perm $_{t-2}$ & 0.4341 & 2.1178 & 1.0551 & 1.9998 \\
\hline$\Delta$ Perm $_{t-3}$ & 0.3992 & 2.4669 & 0.5892 & 1.0225 \\
\hline$\Delta$ Perm $_{t-4}$ & -0.1200 & -0.7611 & 0.1734 & 0.4975 \\
\hline$\Delta$ Start $_{t-1}$ & -0.4315 & -1.5308 & -1.1332 & -2.8165 \\
\hline$\Delta$ Start $_{t-2}$ & -0.5714 & -2.4753 & -1.0838 & -1.8465 \\
\hline$\Delta$ Start $_{t-3}$ & -0.0218 & -0.1150 & -0.0221 & -0.0466 \\
\hline$\Delta$ Start $_{t-4}$ & 0.1217 & 0.9915 & -0.0593 & -0.2772 \\
\hline Const & 0.1142 & 0.4991 & 0.1224 & 0.5690 \\
\hline$Q 2_{t}$ & -0.0504 & -0.1242 & 0.2650 & 1.1571 \\
\hline$Q 3_{t}$ & -0.4166 & -2.6115 & -0.2079 & -0.9445 \\
\hline$Q 4_{t}$ & -0.2675 & -0.7368 & -0.0141 & -0.0727 \\
\hline$t$ & 0.0024 & 1.5247 & -0.0043 & -0.9068 \\
\hline $\mathrm{AR}(1)$ & -0.7897 & -3.7902 & 0.0409 & 0.0787 \\
\hline $\mathrm{R}^{2}$ & 0.909 & & 0.923 & \\
\hline $\mathrm{R}^{2}$-Adj & 0.824 & & 0.796 & \\
\hline$\sigma$ & 0.182 & & 0.194 & \\
\hline SSR & 0.631 & & 0.414 & \\
\hline Log-L & 23.94 & & 21.68 & \\
\hline $\mathrm{Q}(5)$ & 2.311 & & 1.940 & \\
\hline $\mathrm{Q}(10)$ & 9.793 & & 5.418 & \\
\hline
\end{tabular}

Note: All variables are in logs.

Table 5 presents estimates of equation (6.2) for the fulland restricted-sample periods including an $\mathrm{AR}(1)$ term to flatten the correlogram. ${ }^{44}$ As before, findings do not appear to be sensitive to the extreme price volatility in 1981 . Focusing on the full-sample results, as expected, lagged permits have a positive, highly significant impact on current starts, and the impact of permits declines with the length of the lag. Also, permits issued more than three quarters ago have no effect on starts, consistent with anecdotal evidence that most residential building permits issued in Vancouver, B.C., expire within nine months. In addition, nominal interest rates have a negative and highly significant impact on starts (the elasticity is -0.11), while inventories have a negative and marginally significant impact. ${ }^{45}$ In contrast, new building price shocks have no affect on housing starts. Indeed, the coefficient on $e_{t, 5}$ is close to zero and has a very low $t$-ratio.

Evidence that builders do not adjust starts in response to current deviations between new building prices and construction costs could be considered surprising, given that several such deviations were quite large during the 1980s. Consider

\footnotetext{
${ }^{44}$ Jarque-Bera tests for normality cannot reject the null that the error terms are distributed normal. Also, results were little changed by inclusion of an MA(1) term instead of the AR(1) term. Similarly, OLS yielded essentially the same results as those described above. On the other hand, inclusion of the AR(1) term appeared to do a better job of flattening out the residuals' correlogram than other specifications tested. Finally, similar results to those in table 5 were obtained when permits (PERM) were used as the dependent variable.

${ }^{45}$ These results are consistent with those of Clayton (1994) and DiPasquale and Wheaton (1994).
}

Table 6.-Single-Family Homes Under Construction But Not Yet CoMPLETED

\begin{tabular}{|c|c|c|c|c|c|}
\hline Variable & Coeff & t-ratio & Variable & Coeff & $t$-ratio \\
\hline Const & -169.86 & -1.325 & $\Delta$ Start $_{t-2}$ & 0.4758 & 2.756 \\
\hline$Q 2$ & -0.3874 & -0.002 & $\Delta$ Start $_{t-3}$ & 0.1847 & 1.167 \\
\hline$Q 3$ & -126.83 & -1.008 & $\Delta$ Start $_{t-4}$ & -0.0017 & -0.010 \\
\hline$Q 4$ & -46.473 & -0.339 & $\Delta$ Start $_{t-5}$ & 0.1204 & 0.727 \\
\hline$t$ & 8.4237 & 2.620 & $\Delta$ Start $_{t-6}$ & -0.0486 & -0.288 \\
\hline$\Delta$ Start $_{t}$ & 0.8078 & 4.461 & $\Delta$ Start $_{t-7}$ & -0.1532 & -0.972 \\
\hline$\Delta$ Start $_{t-1}$ & 1.3048 & 7.214 & $\Delta$ Start $_{t-8}$ & -0.1006 & -0.648 \\
\hline $\mathrm{R}^{2}$ & 0.901 & $\sigma$ & 147.6 & & \\
\hline SSR & 457,882 & DW & 1.697 & & \\
\hline
\end{tabular}

Note: All variables are in levels.

table 6, however, which presents OLS estimates of the first difference of $U N C_{t}$ - the number of residential buildings currently under construction (not in logs) - on current and lagged first differences of the level of housing starts, $S T R T_{t}$, along with seasonal dummies and a time trend. ${ }^{46}$ The coefficients on the current and one-quarter lagged values of $S T R T_{t}$ are close to and not significantly different from 1, while the coefficients on the second- and third-quarter lags are 0.47 and 0.18 , respectively, after which lagged values of $S T R T_{t}$ have no effect on current construction. These results suggest that single-family detached homes take two to three quarters to build, because one cannot reject the null that homes started in the past quarter have a one-for-one effect on current construction, while homes started more than three quarters ago have no effect on current construction. Comparing that result to earlier findings, it appears that construction lags are sufficiently long as to prevent most builders from profitably exploiting information about contemporaneous deviations between new building prices and construction costs.

\section{Conclusions}

Present-value studies of asset market efficiency are controversial because they compare asset prices to unobserved fundamental values. This forces researchers to confront the difficult problem of how to forecast future rents, a problem that has caused Flood and Hodrick (1990) to question the findings from a wide range of present-value studies. As an alternative, this paper draws on two equilibrium conditions pertinent to the housing market that depend on only current and past values. In long-run equilibrium, the price of a newly constructed building (where building denotes the physical structure as distinct from the land) equals current construction costs. This implies that deviations between new building prices and construction costs should disappear more quickly than the time required for construction. Otherwise, builders would earn excess returns from observed deviations between building prices and construction costs and would adjust their output accordingly. In addition, in long-run equilibrium, expected risk-adjusted rates of return across assets will be equal. Assuming that investors view differentvintage buildings as close substitutes, then, following a

\footnotetext{
${ }^{46}$ Table 6 presents results based on the 1979:1 to 1989:4 period. Similar results were obtained using the 1982:1 to 1989:4 period.
} 
temporary shock, different-vintage building prices should converge back to their long-run values at a similar rate. Otherwise, risk-adjusted returns across different-vintage buildings would differ. ${ }^{47}$ Further, it should be noted that the strategy of comparing rates of price convergence to construction lags could potentially be applied to any manufactured asset, while comparing rates of price convergence across assets has potential applications to asset markets in general.

Data for the study were based on a spatially concentrated set of single-family detached homes sales in Vancouver, B.C., over the 1979:1 to 1989:4 period. Hedonic methods were used to construct fixed-weight, quality-adjusted measures of the price of different-vintage buildings and of vacant land. An error-correction model (ECM) was then estimated using the Engle-Granger (1987) two-step method.

Although new building prices deviated significantly from construction costs several times over the 44-quarter horizon, results from the cointegrating equations support the long-run relationships above. Further, new building price shocks have no discernable effect on construction and largely disappear within two quarters. By comparison, two to three quarters are required to complete a new single-family building. Thus, transactions costs - as measured by the time to complete a building - appear to prevent builders from earning excess profits. In addition, following a shock, older-vintage building prices converge back to equilibrium at the same rate as for new building prices, consistent with the joint hypothesis that investors view different-vintage buildings as close substitutes, and that different-vintage properties yield equal expected returns. Together, these results suggest that the market for residential buildings is efficient. Moreover, these results are robust to the sample period analyzed, the method of constructing the price indices, the method used to estimate the error-correction models, and the specification of those models.

Finally, buildings account for well over $50 \%$ of residential house value in most cities. Findings from this study, therefore, suggest that the principle component to residential housing - namely, the building itself-appears to be priced in an efficient manner. If housing markets are inefficient, as claimed by Case and Shiller (1989) and others, the inefficiency must reside in the market for land itself.

\section{REFERENCES}

Brueckner, Jan, "A Vintage Model of Urban Growth," Journal of Urban Economics 8 (1980), 389-402.

Capozza, Dennis, and Robert W. Helsley, "The Stochastic City," Journal of Urban Economics 26 (1989), 295-306.

Case, Karl E., and Robert J. Shiller, "The Efficiency of the Market for Single Family Homes," American Economic Review 79 (1989), $125-137$.

"The Analytical Economist: Bursting Bubbles," Scientific American (May 1991), 125.

\footnotetext{
${ }^{47}$ These arguments suggest that construction lags have a direct effect on the rate at which new building prices converge to equilibrium following a shock, and an indirect effect on existing building prices, because of the willingness of investors to substitute new buildings for existing ones.
}

Childs, Paul D., Timothy J. Riddiough, and Alexander J. Triantis, "Mixed-Uses and the Redevelopment Option," Real Estate Economics 25 (1997), 317-340.

Clayton, Jim, "Three Essays on Expectations and Housing Price Volatility," Ph.D. Thesis, University of British Columbia, Commerce Department (1994).

Cochrane, John H., "A Critique of the Application of Unit Root Tests," Journal of Economic Dynamics and Control 15 (1991), 275-284.

DiPasquale, Denise, and William C. Wheaton, "Housing Market Dynamics and the Future of Housing Prices," Journal of Urban Economics 35 (1994), 1-27.

Donaldson, Glen R., and Mark Kamstra, "Using Dividend Forecasting Models to Reject Bubbles in Asset Prices: the Case of The Crash of 1929," Review of Financial Studies, 9 (1996), 333-363.

Engelhardt, Gary, and James Poterba, "House Prices and Demographic Change: Canadian Evidence," Regional Science and Urban Economics 21 (1992), 573-579.

Engle, R. F., and C. W. J. Granger, "Cointegration and Error Correction: Representation, Estimation and Testing," Econometrica 55 (1987), 251-276.

- In C. W. J. Granger and G. E. Mizon (eds.), Long-Run Economic Relationships, (New York: Oxford University Press, 1991).

Engle, R. F., and B. Sam Yoo, "Cointegrated Economic Time Series: An Overview with New Results," in R. F. Engle and C. W. J. Granger (eds.), Long-Run Economic Relationship (New York: Oxford University Press, 1991).

Faust, J., "Near Observational Equivalence and Unit Root Processes: Formal Concepts and Implications," Federal Reserve Board Working Paper (1993).

Flood, Robert, and Robert Hodrick, "On Testing for Speculative Bubbles," Journal of Economic Perspectives 5 (1990), 124-150.

Froot, Kenneth A., and Maurice Obstfeld, "Intrinsic Bubbles: The Case of Stock Prices," American Economic Review 81 (1991), 1189-1214.

Gregory, Allan, "Testing for Cointegration in Linear Quadratic Models," Journal of Business and Economic Statistics 12 (1994), 347-360.

Hosios, Arthur, and James Pesando, "Measuring Prices in Resale Housing Markets in Canada: Evidence and Implications," Journal of Housing Economics 1 (1991), 303-317.

Johansen, Søren, "Estimation and Hypothesis Testing of Cointegration Vectors in Gaussian Vector Autoregressive Models," Econometrica 59 (1991), 1,551-1,580.

Linneman, Peter, "An Empirical test of the Efficiency of the Housing Market," Journal of Urban Economics 20 (1986), 140-154.

MacKinnon, James G., "Critical Values for Cointegration Tests," in R. F. Engle and C. W. J. Granger (eds.), Long-Run Economic Relationship (New York: Oxford University Press, 1991).

Mankiw, N. G., and D. N. Weil, "The Baby Boom, The Baby Bust, and the Housing market," Regional Science and Urban Economics 19 (1989), 235-258.

Meese, Richard, and Nancy Wallace, "Residential Housing Prices in the San Francisco Bay Area: New Tests of the Explanatory Power of Economic Fundamentals," unpublished mimeograph, University of California-Berkeley, Haas School of Business (December 1993). "Testing the Present Value Relation for Housing Prices: Should I Leave My House in San Francisco?" Journal of Urban Economics 35 (1994), 245-266.

Munneke, Henry, "Redevelopment Decisions for Commercial and Industrial Properties," Journal of Urban Economics, 39 (1996), 229253.

Rosen, Kenneth T., Seasonal Cycles in the Housing Market: Patterns, Costs, and Policies (Cambridge, MA: MIT Press, 1979).

Rosenthal, Stuart, and Robert Helsley, "Redevelopment and the Urban Land Price Gradient," Journal of Urban Economics 35 (1994), 182-200.

Shiller, Robert, "Do Stock Prices Move Too Much to be Justified by Subsequent Changes in Dividends," American Economic Review 71 (1981), 421-436.

Somerville, Tsur C., "Analyzing Construction Costs: Builder Behavior and Sub-Contractor Reputation in Homebuilding," unpublished mimeograph, Commerce Dept., University of British Columbia (August 1994).

Stiglitz, Joseph, "Symposium on Bubbles," Journal of Economic Perspectives 4 (1990), 13-18. 
Stock, James H., "Asymptotic Properties of Least-Squares Estimators of Co-integrating Vectors," Econometrica 55 (1987), 1,035-1,056.

Titman, Sheridan, "Urban Land Prices Under Uncertainty," American Economic Review 75 (1985), 505-514.

Wheaton, William C., "Urban Spatial Development With Durable But Replaceable Capital," Journal of Urban Economics 12 (1982), 53-67.

Williams, Joseph, "Redevelopment of Real Assets," Real Estate Economics 25 (1997), 387-408.

\section{APPENDIX}

\section{Construction of the Vacant Land and Building Price Series}

To clarify how the vacant land and building price series were constructed, consider the following hedonic equation,

$$
P_{t_{j i}}^{D}=\lambda_{t} Z_{t_{j}}+\beta_{1, t} X_{1, t_{j i}}+\beta_{2, t} X_{2, t_{j i}}+e_{t_{j i}}
$$

where $X_{1, t_{i j}}$ and $X_{2, t_{i j}}$ compose the full set of structural attributes for house $i$ at time $t, Z_{t_{j}}$ is the complete set of locational attributes at location $j$ and time $t$, and $Z_{t}$ does not vary within neighborhoods. ${ }^{48}$

Suppose now that $Z_{t i}, X_{1, t_{i j}}$, and $X_{2, t_{j i}}$ are all observed. Then, given quarterly estimates of equation (A.1) one could construct fixed-weight, quality-adjusted price indices for buildings and vacant land as follows. For buildings,

$$
q_{t}^{B}=\beta_{1, t} \bar{X}_{1}+\beta_{2, t} \bar{X}_{2},
$$

where the overbars stand for the average value of $X_{1}$ and $X_{2}$ over all homes in all time periods. Thus, $q_{t}^{B}$ equals the price of a given type of (standard) building $\left(\bar{X}_{1}, \bar{X}_{2}\right)$, and varies over time with changes in the implicit price of the structural attributes $\left(\beta_{1, t}, \beta_{2, t}\right)$. For vacant land,

$$
q_{t}^{L}=\lambda_{t} \bar{Z}_{t}
$$

where the overbar stands for the average value of $Z_{t}$ over all locations for a given period $t$. Thus, $q_{t}^{L}$ equals the price of a parcel of land for a given "standard" location, and $q_{t}^{L}$ varies over time both with changes in the implicit price of the locational attributes, $\lambda_{t}$, as well as with changes in the locational attributes, $\bar{Z}_{t}$, at the standard location.

Suppose, now that $X_{1, t_{j i}}$ and $Z_{t_{j}}$ are unobserved, $X_{2, t_{j i}}$ is observed, and

$$
X_{1, t_{j i}}=a_{t} X_{2, t_{j i}}+u_{t_{j i}}
$$

where $a_{t}$ is the correlation between the observed and unobserved structural attributes in period $t$, and $\mathrm{E}\left[u_{t}\right]=0$ for all $t$. Substituting equation (A.4) into equation (A.1) and denoting $\lambda_{t} Z_{t_{j}}$ by $\gamma_{t_{j}}$ to simplify notation,

$$
P_{t_{j i}}^{D}=\left(\gamma_{t_{j}}+\bar{u}_{t_{j}}\right)+\left(a_{t} \beta_{1, t}+\beta_{2, t}\right) X_{2, t_{j i}}+\left(e_{t_{j i}}+u_{t_{j i}}-\bar{u}_{t_{j}}\right),
$$

where $\bar{u}_{t_{j}}$ is the average value of $u_{t_{j i}}$ in $j$. Observe also that the first term in parentheses, $\left(\gamma_{t_{j}}+\bar{u}_{t_{j}}\right)$, is a location-specific fixed effect for period $t$, and that $X_{1}$ does not appear in the equation. Thus, fixed-effect estimates of equation (A.5) can be obtained given $X_{2, t_{j i}}$ and information on the location of the different properties.

Consider now the building price series and note that averaging equation (A.4) within a given period gives $\bar{X}_{1, t}=a_{t} \bar{X}_{2, t}$ for each $t$. Then, if $a_{t}$ is constant over time, the second term on the right-hand side of equation (A.5) can be used to form

$$
q_{t}^{B}=\left(\bar{a} \beta_{1, t}+\beta_{2, t}\right) \bar{X}_{2}=\beta_{1, t} \bar{X}_{1}+\beta_{2, t} \bar{X}_{2} .
$$

Expression (A.6) indicates that, if the correlation between the omitted and included structural attributes $\left(a_{t}\right)$ is constant over time, quarterly estimates of equation (A.5) can be used to construct a fixed-weight building price series.

${ }^{48}$ More generally, for the arguments below, it is sufficient to assume that, within neighborhoods, the characteristics of individual homes are not correlated with variation in locational attributes. As discussed in the text, the data likely satisfy that condition.
Table A-1.-Vacant Land and New Building Prices Based on the REDEVELOPMENT AND DECOMPOSITION METHODOLOGIES

\begin{tabular}{lccccc}
\multicolumn{3}{c}{ REDEVEOPMENT AND DECOMPOSITION METHODOLOGIES } \\
\hline \hline & \multicolumn{2}{c}{ Land Price Series } & & New Building Price Series \\
\cline { 2 - 3 } \cline { 5 - 6 } \cline { 5 - 6 } & Decomp & Redevelop & & Decomp & Redevelop \\
\hline Mean & 64.03 & 78.97 & & 55.30 & 40.35 \\
Median & 61.60 & 71.89 & & 51.45 & 36.17 \\
Maximum & 102.4 & 135.5 & & 134.1 & 110.1 \\
Minimum & 37.18 & 59.11 & & 25.57 & 16.95 \\
Std. Dev & 14.46 & 18.48 & & 19.61 & 17.12 \\
Correlation & 0.680 & - & & 0.730 & - \\
\hline
\end{tabular}

Note: Sample Period: 1979:1 to 1988:4. All values are in 1979:1 \$1,000 units.

Figure A-1.-Vacant Land Prices Based on RedeVeloped Properties AND THE DECOMPOSITION METHODOLOGY

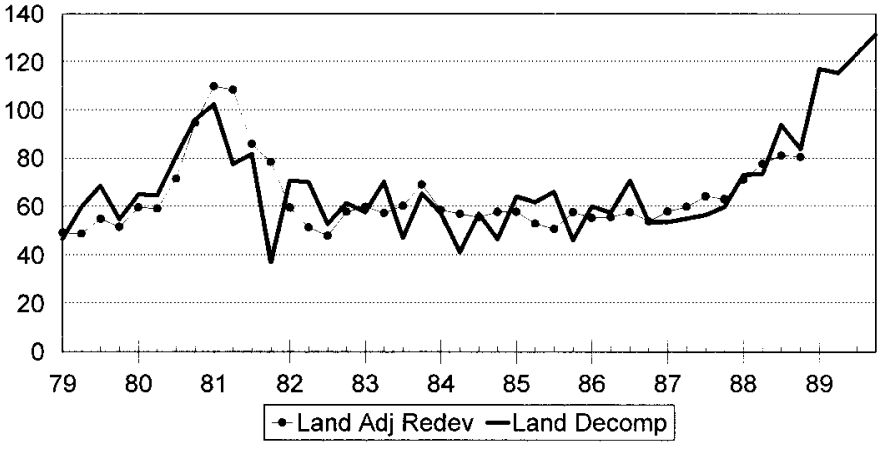

The price series based on redevelopments is adjusted by a scalar to force the means (over the common sample) of the two land price series to be equal. (All variables are in 1979:1 \$1,000 units.)

Figure A-2.-New Building Prices Based on Redeveloped Properties AND the DeComposition Methodology

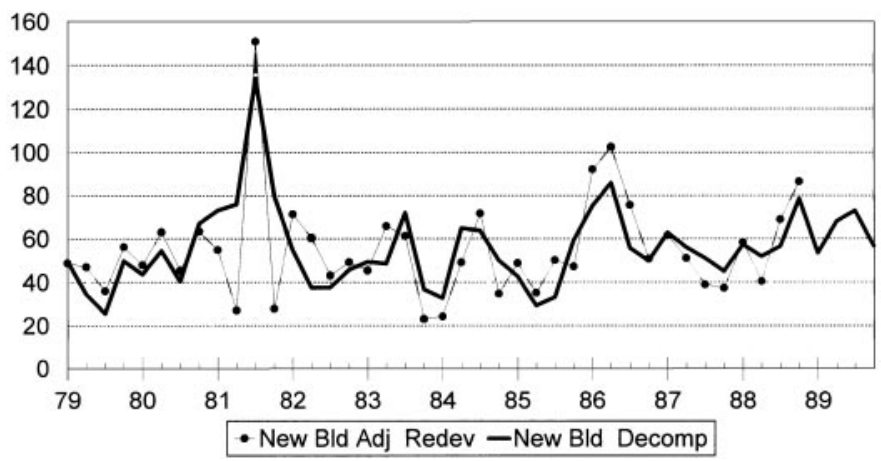

The price series based on redevelopments is adjusted by a scalar to force the means (over the common sample) of the two building price series to be equal. (All variables are in 1979:1 \$1,000 units.)

Now, define $s_{t_{j}}$ as the proportion of home sales in location $j$ and period $t$, and suppose that $s_{t_{j}}$ is constant over time, or $s_{t_{j}}=\bar{s}_{j}$. Then,

$$
q_{t}^{L}=\sum_{j=1}^{J} \bar{s}_{j}\left(\gamma_{t_{j}}+\bar{u}_{t_{j}}\right)=\gamma_{t},
$$

where the second equality holds because $\mathrm{E}\left[u_{t}\right]=0$ for all $t$. Expression (A.7) indicates that if the neighborhood shares of home sales, $s_{t}$, are constant over time, estimates from equation (A.4) can be used to construct the quality-adjusted price of vacant land.

In principle, the price of vacant land can also be estimated by examining properties that have sold for redevelopment (e.g., Rosenthal \& Helsley, 1994). Unfortunately, direct data on which properties sold for redevelopment were not available for the long time series in this paper. As an alternative, properties for which multiple sales were observed and for which the structure appeared to have been replaced within four years after the first sale date were assumed to have been initially sold for redevelopment. Under the assumption that these properties— 850 in total—had been 
sold for redevelopment, an alternative quality-adjusted vacant land price series was constructed. ${ }^{49}$ Subtracting that series from the quality-adjusted price of a new standard home as obtained from the main data set yielded an alternate series for the price of a newly constructed building as well Before comparing these series to those in the text, however, the reader is cautioned that the repeat sales-based series are provided only as a rough check on robustness and are not intended to provide a rigorous check on the overall methodology used in this paper. ${ }^{50}$

Summary statistics for the two sets of series are provided in table A-1. Note that the means of the decomposition- and redevelopment-based series

${ }^{49}$ To construct the repeat sales-based vacant land price series, quarterly house price regressions were first estimated including only locational dummy variables and lot size as regressors, because demolition costs for single-family detached homes in Vancouver are quite small [e.g., Rosenthal \& Helsley, 1994). Quality-adjusted measures of the price of vacant land were then constructed using the same values for the neighborhood weights $\bar{s}_{j}$ ) and the same standard size lot as for the main data set.

50 The repeat-sales procedure may incorrectly label some properties as redevelopments, especially to the extent that some properties are redevel- differ by roughly $\$ 15,000$. After scaling the means of the redevelopmentbased series to equal that of the decomposition-based series, the alternative series track each other quite closely over time. In figures A-1 and A-2, the correlation between the land price series is 0.68 , while the correlation between the new building price series is 0.73 .

oped up to four years after the initial transaction date (or there is coding error in the structure-age variable). In addition, the repeat-sales procedure does not control for possible sample-selection bias associated with the endogenous decision to redevelop a property. Further, the repeat-sales sample includes only 850 homes, far fewer than the 25,000 homes in the main data set. Given that there are 44 quarters, the relatively small sample of repeat sales increases the noise around any given land price estimate. Finally, the two alternative building price series are not independently constructed given that the quality-adjusted house price series - as derived from the decomposition method-is used in both cases. For these reasons, comparisons in table A-1 should be viewed with some caution. 